\title{
Brachycorythis peitawuensis (Orchidaceae) is non-endemic and significantly more variable than previously perceived
}

\author{
Pedersen H.ÆE. ${ }^{1,2}$, Nuammee A. ${ }^{3}$ \& S. Watthana ${ }^{4 *}$ \\ ${ }^{1}$ Natural History Museum of Copenhagen, Gothersgade 130, DK-1123 Copenhagen K, Denmark \\ ${ }^{2}$ Herbarium, Science, Royal Botanic Gardens, Kew, Richmond, Surrey, England TW9 3AE, UK \\ ${ }^{3}$ Queen Sirikit Botanic Garden, P.O. Box 7, Mae Rim, Chiang Mai - 50180, Thailand \\ ${ }^{4}$ School of Biology, Institute of Science, Suranaree University of Technology, Suranaree Subdistrict, 111 University Avenue, Muang \\ District, Nakhon Ratchasima - 30000, Thailand \\ ^E-mail: santiqsbg@gmail.com
}

\begin{abstract}
New species are often being described soon after their discovery at just a single site - and will appear narrowly endemic until additional populations (if any) are discovered elsewhere. The process of realizing that an initially "apparent endemic" is in reality non-endemic can be delayed if disjunct populations are redundantly described as distinct species - a risk that probably is negatively correlated with the range of morphological variation reported for the initially discovered population(s). Prompted by recent finds of some aberrant Brachycorythis plants in Thailand, we reassessed the morphological variation and distribution status of Brachycorythis peitawuensis T.P.Lin \& W.M.Lin. - a species up to now considered endemic to Mt. Peitawu in Taiwan. Comparisons of the Thai material with the protologue and holotype of B. peitawuensis, and with a more recently published account on the Mt. Peitawu population, unequivocally indicated that also the newly collected plants from Thailand belong to this species. To assist future identification of B. peitawuensis, an amended description is provided, based on previously published data from Taiwan and our original observations from Thailand.
\end{abstract}

Keywords: Colour morphs, Disjunctions, Flora of Taiwan, Flora of Thailand, Intraspecific variation, Rarity.

\section{Introduction}

Endemic species tend to attract special conservation attention, as they are generally more vulnerable than non-endemic species (Ișik, 2011). Not only do their

Received: 09.03.2020; Revised \& Accepted: 17.06.2021

Published Online: 16.10.2021 narrow ranges make them more susceptible to stochastic threats such as fire and drought (Murray et al., 2017), they are also among the preferred targets of collectors. As far as endemic orchids are concerned, the collection threat mainly pertains to attractive, large-flowered species such as Paphiopedilum vietnamense O.Gruss \& Perner (Averyanov et al., 2001) and Phragmipedium kovachii J.T.Atwood, Dalström \& Ric. Fernández (Cribb, 2005). Little is known about the factors which are the most important for restricting ranges of endemic species, but, at least in some cases, restrictions on reproductive attributes seem to contribute (Srimuang et al., 2010) as do higher levels of integration within and between phenotypes and environments (Hermant et al., 2013). Probably, one of the reasons for our poor insight in this field is that our knowledge of individual species ranges needs time to develop. Thus, new species are often being described soon after their discovery in just one small geographic area - and will appear narrowly endemic until additional populations of the same species (if any) are discovered elsewhere. The process of realizing that an initially "apparent endemic" is in reality non-endemic can be severely delayed if disjunct populations are redundantly described as distinct species (e.g., Bunpha et al., 2013; Geiger, 2019) - a risk that probably is negatively correlated with the range of morphological variation reported for the initially discovered population(s). In this paper, we reassess the morphological variation and distribution status of 


\section{Brachycorythis peitawuensis T.P.Lin \& W.M.Lin.}

Up to now, B. peitawuensis has been considered endemic to Mt. Peitawu in southern Taiwan. According to the protologue, this species "... is well characterized by its single showy flower, ...” (Lin \& Lin, 2009). Indeed, the consistently one-flowered condition observed in B. peitawuensis seemed unique, whereas the floral dimensions indicated in the protologue were broadly overlapping with those of several other species (Summerhayes, 1955; Pedersen, 2010, 2011). Though not emphasized in the protologue, the obliquely funnel-shaped conformation of the labellum, clearly described and illustrated for B. peitawuensis, was a trait previously unknown for Asian members of Brachycorythis Lindl. Moreover, the largely (and consistently) white labellum colour (Lin \& Lin, 2009) added to the impression of a well-defined and little variable species.

In 2011, one of us (S. Watthana) collected a live Brachycorythis plant near Ban Huai Tham Suea, Mae Sot district, Tak province, Thailand. That plant flowered in cultivation in Queen Sirikit Botanic Garden in August 2012, and, in the same month, we came across similar flowering individuals in a private nursery in the province of Chiang Mai. According to the owner, the latter plants had been purchased from a market in Mae Sot and were, allegedly, of local provenance. The obliquely funnel-shaped labellum of all these Brachycorythis plants clearly indicated that they did not belong to any species previously known from Thailand, and it rather suggested B. peitawuensis. However, the Thai plants differed from the latter in being 5 to 8-flowered (Fig. 1a-b) and in some of the individuals having flowers with a purple labellum (Fig. 1c). Considering the huge distance to the only confirmed site of B. peitawuensis (c. $2300 \mathrm{~km})$, these conflicting signals left us in doubt whether the Thai plants should be identified as B. peitawuensis or described as a new species. Below, we outline the methods and report the results and conclusions of our investigation.

\section{Materials and Methods}

To assess whether the newly collected plants from Thailand belonged to B. peitawuensis, we recorded their range of variation in virtually all morphological characters included in the original description of the latter (Lin \& Lin, 2009). Character by character, we compared the variation observed in Thai material with the original description and line drawing of B. peitawuensis, with the holotype of the latter, and with the short account (description, colour photos) on B. peitawuensis in Lin and Wang (2014).

\section{Results}

Our detailed comparison between morphological variation in the unidentified Thai material and original Taiwanese material of $B$. peitawuensis (as scored from the protologue and holotype), left us with the impression that we were dealing with only one species - though with the large and consistent difference in inflorescence size (1-flowered in Taiwan versus 5 to 8 -flowered in Thailand) representing a major discrepancy. However, the description and colour photos of Taiwanese $B$. peitawuensis published by Lin and Wang (2014) demonstrated that the only known population in Taiwan is more variable in a few morphological characters than originally observed. Most importantly, Lin and Wang (2014) reported inflorescences with 1-5 flowers, thus completely closing the apparent gap in this character between Thai and Taiwanese material.

\section{Discussion}

Based on the results of our comparisons, we are convinced that the cited Brachycorythis material from Thailand belongs to B. peitawuensis. This means that the species should no longer be considered endemic to Mt. Peitawu in southern Taiwan. On the contrary, its newly recognized occurrence in Thailand dramatically increases the species' geographic range. The future will show whether the distribution continues to appear disjunct, or whether B. peitawuensis is scattered, 
though probably rare, in major parts of South-east Asia.

The short account on B. peitawuensis in Lin and Wang (2014) improved the knowledge of variation in this species, and the results of our examination of Thai material further demonstrate that $B$. peitawuensis is significantly more variable than previously perceived. A few comparative examples of single-character variation, as observed by Lin and Lin (2009), Lin and Wang (2014) and us, are shown in Table 1. The discovery in Tak province, Thailand of a colour morph with deep purple labellum lamina (Fig. 1c) is particularly noteworthy. To date, no intermediate colour morph has been reported, but this likely reflect data deficiency, as most other Asian Brachycorythis species have highly variable flower colour, often ranging from white to dark purple (Pedersen, 2011). In the "Taxonomic Treatment" below, we provide an amended description of $B$. peitawuensis to assist future identification of this species; the description incorporates previously published data from Taiwan (Lin \& Lin, 2009; Lin \& Wang, 2014) and our original observations from Thailand.

The present case demonstrates the importance of thorough species descriptions that do not only include all relevant characters, but also cover the maximum range of variation that can be observed in each character. Although paucity of material often reduces the practical possibilities (as it might well have done in connection with B. peitawuensis), the coverage of variation within each individual character should be maximized in the description in any protologue. Thorough descriptions in protologues represent the first important step to avoid future redundant descriptions of the same species under different names.

\section{Taxonomic Treatment}

Brachycorythis peitawuensis T.P.Lin \& W.M.Lin, Taiwania 54: 323. 2009. Type: TAIWAN, Pingtung County, Mt. Peitawu, N 22 37'31", E 12044'55", 1500 m, December 2008, flowering in cultivation 03.08.2009, Yi-Fu Wang s.n. (holo TAI 268953 [images!]).

Fig. 1

Terrestrial herb with a pair of sub-spherical to obovoid or ellipsoid underground tubers, 1.4-2.2 cm long, 1.2-1.7 cm across; roots produced from underground part of stem, unbranched, up to 4.2 $\mathrm{cm}$ long, 1-2 $\mathrm{mm}$ across. Flowering shoots erect, 10-24.5 cm tall; stem terete, $2.5-3 \mathrm{~mm}$ across at middle, 2-2.5 mm across just below inflorescence, glabrous, green; cataphylls c. 3, sheathing, producing vestigial, up to $1.5 \mathrm{~cm}$ long lamina.

Table 1. Examples of morphological characters that have turned out more variable in Brachycorythis peitawuensis T.P.Lin \& W.M.Lin over the years. A dash indicates that the character is not included in the description concerned.

\begin{tabular}{|c|c|c|c|}
\hline Characters & Lin and Lin (2009) & Lin and Wang (2014) & Thailand, new original data \\
\hline Plant height $(\mathrm{cm})$ & c. 20 & $15-20$ & $10-24.5$ \\
\hline Leaf length $(\mathrm{cm})$ & up to 9.3 & $6-9$ & $\begin{array}{l}\text { [longest leaf]: 6-9.9 } \\
\text { [uppermost leaf]: 6-9 }\end{array}$ \\
\hline Leaf width $(\mathrm{cm})$ & 2.3 & $2-2.3$ & $\begin{array}{l}\text { [longest leaf]: } 1.6-2.3 \\
\text { [uppermost leaf]: } 1.5-2.6\end{array}$ \\
\hline $\begin{array}{l}\text { Leaf colour } \\
\text { (upper surface) }\end{array}$ & Green & Green & $\begin{array}{l}\text { Mid-green to light green and } \\
\text { sometimes with purple mid-line }\end{array}$ \\
\hline Flower number & 1 & $1-5$ & $5-8$ \\
\hline Labellum, apex & Acute & - & emarginate to subacute \\
\hline Labellum - colour & $\begin{array}{l}\text { Yellow on basal part, } \\
\text { central lane greenish, } \\
\text { front limb white }\end{array}$ & $\begin{array}{l}\text { White, disc flushed } \\
\text { with light green or } \\
\text { yellow }\end{array}$ & $\begin{array}{l}\text { Mainly white or purple, but } \\
\text { usually yellow to green in its } \\
\text { basal to central part }\end{array}$ \\
\hline
\end{tabular}



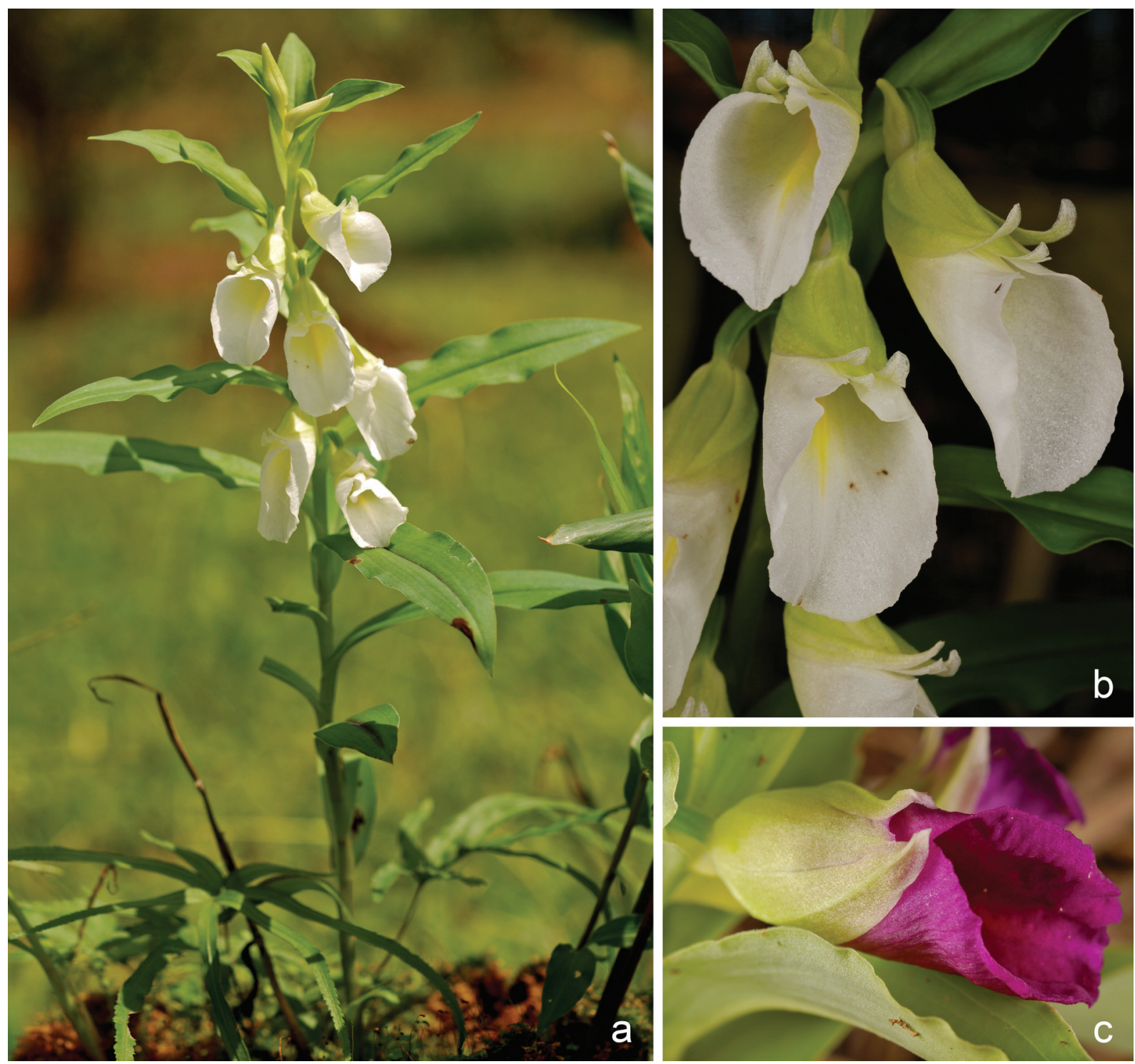

Fig. 1. Brachycorythis peitawuensis T.P.Lin \& W.M.Lin, individuals from Thailand: a. Habit of white colour morph; b. Flowers of white colour morph; c. Flower of purple colour morph (photos by H.ÆE. Pedersen).

Foliage leaves 7-9, alternate, placed $1.2-1.4 \mathrm{~cm}$ apart on average, sheathing (below) to nonsheathing (above), sessile, spreading to sub-erect, straight to moderately recurved, (ob)lanceolate to lanceolate-elliptic, often slightly oblique, lightly keeled, acute, minutely mucronate, mid-green to light green (and sometimes with purple mid-line) above, pale green underneath; margin flat to distinctly undulate; longest leaf 6.9-9.9 × 1.6-2.3 $\mathrm{cm}, 5.8-7.3$ times as long as average internode length; uppermost leaf $6-9 \times 1.5-2.6 \mathrm{~cm}, 1.1-1.2$ times as long as the lowermost bract. Inflorescence spicate, up to $10 \mathrm{~cm}$ long; bracts leaf-like, longer than the flowers, spreading to sub-erect, straight to moderately recurved, (ob)lanceolate to lanceolate-elliptic, often slightly oblique, acute, minutely mucronate, coloured as foliage leaves (though consistently without purple mid-line); margin flat to undulate; lowermost (i.e., longest) bract 5.5-7.6 × 1.5-2.1 cm. Flowers 1-8, resupinate, nodding, weakly sweet-scented. Sepals shallowly boat-shaped, more or less recurved in their distal part, light green to whitish-green; dorsal sepal porrect, (ovate-)lanceolate, 13.2-18 × 5.2-7.4 mm, rounded to acute, sometimes minutely mucronate; lateral sepals slightly spreading, obliquely to 
falcately (linear-)lanceolate, widest below the middle, 16.3-20 × 4.8-7.4 mm, longer than dorsal sepal, rounded to acuminate. Petals free from column, connivent with dorsal sepal, more or less recurved in their distal part, obliquely to falcately (oblong-) lanceolate to linear-lanceolate, widest below middle, $13.5-18 \times 3.7-5.8 \mathrm{~mm}$, rounded to obtuse, light green to whitish-green. Labellum spurred at base; lamina porrect, obliquely funnelshaped (i.e., convolute or very nearly so) with slightly recurved front margin, indented along midline, sub-orbicular to very broadly (ob)ovate when flattened, $20-32 \times 25.7-34.9 \mathrm{~mm}, 0.8-0.9$ times as long as wide, emarginate to acute, provided with two short keels in front of spur entrance, mainly white or purple, but usually yellow to green in its basal to central part; spur parallel to ovary, conicalcylindric, moderately compressed, 8-10.1 mm long, $3.5-3.8 \mathrm{~mm}$ in vertical diameter at entrance, $0.8-$ $0.9 \mathrm{~mm}$ in vertical diameter $1 \mathrm{~mm}$ below apex, white to cream or whitish-green. Column subterete with two lateral auricles, $4.5-5 \mathrm{~mm}$ long (to apex of anther), c. $2.5 \mathrm{~mm}$ to apex of auricles, white; anther erect, firmly attached, biloculate, cream; pollinia 2, sectile, with slender caudicles and separate oblong naked viscidia, yellow; stigma transversely elliptic, concave with raised margins; distal part of rostellum erect, squeezed in between anther canals. Ovary curved, fusiform-terete, 12-17.5 mm long, furrowed, white-papillose, light green to midgreen. Capsules not seen.

Flowering \& fruiting: Flowering from August to September; fruiting not observed.

Habitat: Dry dipterocarp forest and broadleaved forest at 400-1500 m.

Distribution: Taiwan and Thailand.

Specimens examined: TAIWAN, Pingtung county, Mt. Peitawu, N 22³7'31", E 12044'55", 1500 m, December 2008, flowering in cultivation 03.08.2009, Yi-Fu Wang s.n. (TAI [268953] images). THAILAND, Tak province, Mae Sot, Ban Huai Tham Suea, 400 m, July 2011, flowering in cultivation in Queen Sirikit Botanic Garden
20.08.2012, Watthana 4121 (QBG [58390]); Mae Sot, s.loc., s.d., flowering in cultivation in a private nursery 14.08.2012, Watthana 4118 (QBG [82138]); Ibid., Watthana 4119 (QBG [82139]).

Notes: Bracycorythis peitawuensis is similar to the members of the B. helferi (Rchb.f.) Summerh. species group, as delimited by Pedersen (2010), but it differs from them all in the obliquely funnel-shaped conformation of its labellum.

\section{Acknowledgements}

We thank Yung-I Lee for providing images of the holotype of B. peitawuensis. Augustinus Foundation supported H.Æ. Pedersen in the initial phase of his participation in the project (grant no. 10-2820).

\section{Literature Cited}

AVERYANOV L.V., PHAN K.L. \& T.H. NGUYEN 2001. The distribution of Paphiopedilum vietnamense and its current status in the wild. Orchid Digest 65: 158-162.

BUNPHA K., PEDERSEN H.Æ. \& K. SRIDITH 2013. Establishing species distributions in large tropical plant genera: insights from twelve new Thai records of Oberonia (Orchidaceae). Blumea 58: 71-76. https:// doi.org/10.3767/000651913X672299

CRIBB P. 2005. Phragmipedium kovachii Orchidaceae. Curtis's Botanical Magazine 22: 8-11, Pl. 511.

GEIGER D.L. 2019. Studies on Oberonia 5 (Orchidaceae: Malaxideae). Twenty-four new synonyms, and a corrected spelling. Blumea 64: 123-139. https://doi.org/ 10.3767/blumea.2019.64.02.04

HERMANT M., PRINZING A., VERNON P., CONVEY P. \& F. HENNION 2013. Endemic species have highly integrated phenotypes, environmental distributions and phenotype-environment relationships. Journal of Biogeography 40: 1583-1594. https://doi.org/10.1111/ jbi.12095

IŞIK K. 2011. Rare and endemic species: why are they prone to extinction? Turkish Journal of Botany 35: 411-417. https://doi.org/10.3906/bot-1012-90

LIN T.P. \& W.M. LIN 2009. Newly discovered native orchids of Taiwan (III). Taiwania 54: 323-333.

LIN, W.M. \& Y.F. WANG 2014. The wild orchids of Taiwan: an illustrated guide. KBCC Press, Gaoshu Township.

MURRAY N.J., KEITH D.A., BLAND L.M., NICHOLSON E., REGAN T.J., RODRÍGUEZ J.P. 
\& M. BEDWARD 2017. The use of range size to assess risks to biodiversity from stochastic threats. Diversity and Distributions 23: 474-483. https://doi.org/10.1111/ ddi. 12533

PEDERSEN H.Æ. 2010. Species delimitation and recognition in the Brachycorythis helferi complex (Orchidaceae) resolved by multivariate morphometric analysis. Botanical Journal of the Linnean Society 162: 6476. https://doi.org/10.1111/j.1095-8339.2009.01015.x

PEDERSEN H.Æ. 2011. Brachycorythis. In: SANTISUK, T. \& K. LARSEN (eds.), Flora of Thailand. Volume 12(1). The Forest Herbarium, Department of National
Parks, Wildlife and Plant Conservation, Bangkok. pp. 21-28.

SRIMUANG K., WATTHANA S., PEDERSEN H.Æ., RANGSAYATORNN.\&D.EUNGWANICHAYAPANT 2010. Aspects of biosubsistence in Sirindhornia (Orchidaceae): are the narrow endemics more reproductively restricted than their widespread relative? Annales Botanici Fennici 47: 449-459. https://doi.org/ 10.5735/085.047.0604

SUMMERHAYES V.S. 1955. A revision of the genus Brachycorythis. Kew Bulletin 10: 221-264. https://doi.org/ 10.2307/4108866 